\title{
EDUCAÇÃO INFANTIL E GESTÃO DEMOCRÁTICA: DESAFIOS DO COTIDIANO PARA A GARANTIA DOS DIREITOS DAS CRIANÇAS
}

\author{
CHILD EDUCATION AND DEMOCRATIC MANAGEMENT: DAILY \\ CHALLENGES FOR THE GUARANTEE OF CHILDREN'S RIGHTS
}

\section{EDUCACIÓN INFANTIL Y GESTIÓN DEMOCRÁTICA: DESAFÍOS DEL COTIDIANO PARA LA GARANTÍA DE LOS DERECHOS DE LOS NIÑOS}

\author{
Maria Aparecida Guedes Monção ${ }^{1}$ \\ ${ }^{1}$ Universidade Estadual de Campinas (UNICAMP), Campinas/SP-Brasil
}

Resumo O texto tem como objetivo problematizar a gestão democrática na educação infantil a partir da análise de algumas situações observadas no cotidiano de uma creche paulistana, que retratam o dia a dia das crianças e a relação estabelecida entre adultos e crianças. Parte do pressuposto de que a finalidade da gestão educacional na primeira infância é a garantia dos direitos fundamentais das crianças por meio da constituição de um contexto educacional norteado por práticas democráticas. Para tanto, pauta-se nos resultados de uma pesquisa de doutorado, cujo estudo empírico foi realizado em um centro de educação infantil (CEI) da rede municipal de São Paulo, por meio de entrevistas semiestruturadas, observação participante e análise documental. No texto, utilizam-se apenas registros do diário de campo relativos às observações da jornada das crianças na instituição. As principais conclusões acenam para a necessidade de se considerar o cotidiano como instrumento potente para reflexão e implementação de práticas democráticas nas instituições de educação infantil.

Palavras-chave: Gestão democrática; EducaÇão infantil; Creche.

Abstract The text aims to problematize the democratic management of children's education based on the analysis of some situations observed in the daily life of a day care center in São Paulo, which portrays the daily life of children and the relationship established between adults and children. It is based on the assumption that the purpose of early childhood education management is to guarantee the fundamental rights of children through the constitution of an educational context guided by democratic practices. To do so, we are based on the 
results of a doctoral research, whose empirical study was carried out at a center for early childhood education (CEI) of the municipal network of São Paulo, through semi-structured interviews, participant observation and documentary analysis. In the text, only records of the field diary relative to observations of the children's journey in the institution are used. The main conclusions point to the need to consider daily life as a powerful tool for reflection and implementation of democratic practices in early childhood education institutions.

Keywords: Democratic management; Child education; Nursery.

Resumen El texto tiene como objetivo problematizar la gestión democrática en la educación infantil a partir del análisis de algunas situaciones observadas en el cotidiano de una guardería paulistana, que retratan el día a día de los niños y la relación establecida entre adultos y niños. Parte del supuesto de que la finalidad de la gestión educativa en la primera infancia es la garantía de los derechos fundamentales de los niños a través de la constitución de un contexto educativo orientado por prácticas democráticas. Para ello, se orienta en los resultados de una investigación de doctorado, cuyo estudio empírico fue realizado en un centro de educación infantil (CEI) de la red municipal de São Paulo, por medio de entrevistas semiestructuradas, la observación participante y análisis documental. En este texto, se utilizan sólo registros del diario de campo relativos a las observaciones de la jornada de los niños en la institución. Las principales conclusiones acentúan la necesidad de considerar el cotidiano como instrumento potente para la reflexión e implementación de prácticas democráticas en las instituciones de educación infantil.

Palabras clave: Gestión democrática; Educación infantil; Guardería infantil.

\section{INTRODUÇÃo}

As creches e pré-escolas constituem-se como os primeiros espaços de educação coletiva fora do ambiente familiar e, por acolherem crianças pequenas e muito pequenas, é fundamental que sejam observadas suas especificidades. Isso não significa excluí-las ou ampliar a fragmentação entre as diferentes etapas da educação básica; ao contrário, o propósito é reconhecer que as crianças de 0 a 5 anos de idade possuem uma particularidade, especialmente por conta da fase de vida em que se encontram. Conhecer a si mesmas e o mundo são os principais desafios das crianças para se apropriarem da cultura humana e, para isso, necessitam da parceria com o adulto e de um ambiente educativo acolhedor, rico em possibilidades de exploração e descobertas. É necessário que, nesse ambiente, as brincadeiras e as interações sejam consideradas o eixo norteador de todo o trabalho pedagógico, e o cuidado e a educação sejam compreendidos e efetivados de forma indissociável.

Uma proposta curricular pautada nas brincadeiras e nas interações como preconizado nas Diretrizes Curriculares Nacionais para a Educação Infantil (DCNEI) revela que a educação infantil tem um caráter diferente de outras etapas da educação básica. Ela não é uma instituição em que se ministram aulas com o mesmo tema, com a intenção de que as crianças aprendam o mesmo conteúdo, ao mesmo tempo. Os conteúdos nessa etapa da vida devem ser amplos e não seguir uma ordem que determine a passagem da criança para outros estágios sequenciais e determinados. 
A organização do tempo, do espaço, dos materiais e do ambiente é aspecto fundamental para se promoverem experiências significativas que favoreçam o desenvolvimento integral da criança. Isso exige o rompimento com o modelo de organização do trabalho pedagógico centrado nas atividades a serem desenvolvidas ou nos conteúdos escolares pautados em áreas de conhecimento que desconsiderem as manifestações, curiosidades e interesses infantis. Busca-se uma nova forma de organização da estrutura institucional, em que o trabalho pedagógico seja compreendido em sua totalidade, garantindo um ambiente lúdico, instigante e acolhedor e a constituição de novas formas democráticas de relacionamento, em que a subjetividade de educadores, crianças e suas famílias, seja considerada e respeitada.

Estabelecer relações democráticas entre os sujeitos que participam do cotidiano das instituições de educação infantil, com vistas a garantir os direitos fundamentais das crianças, demanda, em primeiro lugar, a compreensão de que a criança é um ser competente, sujeito de direitos e foco de todo o trabalho pedagógico. Em segundo lugar, a educação da criança efetivada nas instituições de educação infantil deve ser compartilhada com sua família, constituindo-se como um processo de diálogo e partilha, uma vez que não é possível respeitar os direitos das crianças sem se respeitarem também os direitos de suas famílias. Em terceiro lugar, e não menos importante, essa dinâmica requer a compreensão de que, para dar conta desses dois primeiros objetivos, é necessário que se atente para a formação continuada e as condições de trabalho das professoras ${ }^{1}$ e de toda a equipe educacional, com vistas à constituição de um trabalho coletivo. Tais aspectos constituem a tríade indissociável a ser priorizada nas práticas cotidianas para efetivar a gestão democrática na instituição e guiar a implementação de políticas públicas e a democratização do sistema educacional.

Compreender a especificidade da gestão na educação infantil requer conhecer e analisar como se constitui o cotidiano de uma instituição educacional que atende a crianças pequenas, tendo como norte o fato de que a prática pedagógica deve assegurar seus direitos fundamentais. Assim, o artigo ora apresentado é fruto dos resultados de uma pesquisa de doutorado, cujo estudo empírico foi realizado em um centro de educação infantil (CEI) ${ }^{2}$ da rede municipal de São Paulo, que atende a crianças de 0 a 4 anos de idade em período integral. O texto tem como objetivo problematizar a gestão democrática na educação infantil a partir da análise de algumas situações observadas no CEI pesquisado e que retratam a organização do cotidiano das crianças e a relação estabelecida entre estas e os adultos.

A coleta de dados ${ }^{3}$ foi realizada por meio de entrevistas semiestruturadas, observação participante e análise documental. Por se tratar de um estudo de cunho etnográfico, a

1 Considerando que a maioria que atua diretamente com as crianças são mulheres, optou-se por escrever o termo no feminino.

2 Na rede municipal de educação de São Paulo, as creches são denominadas de centros de educação infantil e atendem a crianças de 0 a 4 anos de idade.

3 O desenvolvimento da pesquisa baseou-se nos princípios éticos definidos pelos Padrões éticos na pesquisa em educação: primeiro documento, elaborado pelo Comitê de Ética na Pesquisa da Faculdade de Educação da Universidade de São Paulo (Feusp), com base na Portaria Feusp nº. 15/2006, de 18 de agosto de 2006. Todos os profissionais e famílias foram devidamente informados quanto ao teor da investigação e consultados no que diz respeito a seu interesse em participar. Ao concordar em participar da pesquisa, foi exibido o Termo de Consentimento Livre Esclarecido para cada sujeito, deixando uma cópia com cada participante. Os nomes de crianças e professoras apresentados no texto são fictícios. 
permanência em campo teve a duração de dois anos; entretanto, o conteúdo apresentado neste texto se refere apenas às observações realizadas ao longo de um ano, com duração de aproximadamente quatro horas semanais, no intuito de conhecer em profundidade o funcionamento e a dinâmica das relações no CEI e compreender o contexto institucional em seu cotidiano, mediante observação participante.

\begin{abstract}
A observação é chamada de participante porque se admite que o pesquisador tem sempre um grau de interação com a situação estudada, afetando-a e sendo por ela afetado. Isso implica uma atitude de constante vigilância, por parte do pesquisador, para não impor seus pontos de vista, crenças e preconceitos. Antes, vai exigir um esforço deliberado para colocar-se no lugar do outro, e tentar ver e sentir, segundo a ótica, as categorias de pensamento e a lógica do outro. A observação participante e as entrevistas aprofundadas são, assim, os meios mais eficazes para que o pesquisador se aproxime dos sistemas de representação, classificação e organização do universo estudado (ANDRÉ, 2008, p. 27).
\end{abstract}

Com o intento de tornar mais "natural" minha presença como pesquisadora, tanto para os profissionais quanto para as crianças, iniciei realizando observações em salas, horários de entrada e saída, horários coletivos e reuniões de pais e de professoras. O registro detalhado das observações no caderno de campo possibilitou identificar e analisar as múltiplas variáveis que compõem a unidade estudada.

A análise dos dados foi realizada a partir de três eixos analíticos: 1) a relação entre professoras e crianças; 2) a relação entre professoras e equipe de gestão; e 3) a relação entre educadores e famílias. A escolha desses eixos foi fruto de um minucioso estudo das observações e depoimentos, buscando a relação com a produção de conhecimentos na área de Educação Infantil e na Educação de modo geral. O conteúdo apresentado neste texto se refere a observações de aspectos relacionados aos eixos 1 e 3 .

O texto está organizado em três partes. Inicialmente, aborda-se a especificidade da educação infantil. Em seguida, discute-se a gestão democrática na educação infantil. A partir das concepções explicitadas nos primeiros itens, na terceira parte do artigo se reflete sobre a importância da análise do cotidiano e da escuta das crianças, compreendendo-os como os eixos norteadores da gestão democrática nas instituições de educação infantil. E, por fim, as considerações finais, em que se assinala o papel da equipe de gestão para a efetivação da gestão democrática.

\title{
As ESPECIFICIDAdeS da EDUCAÇÃO dos bebÊS E dAS CRIANÇAS PEQUENAS NOS CONTEXTOS EDUCACIONAIS COLETIVOS
}

Para efetivar a reflexão sobre gestão democrática na educação infantil, é fundamental atentar para os elementos que constituem a especificidade das instituições educacionais que atendem a bebês e crianças pequenas: 1) a centralidade dos bebês e das crianças pequenas no projeto pedagógico; 2) as interações e brincadeiras como eixo curricular; e 3) a integração entre cuidado e educação, e seu compartilhamento entre educadores e famílias. Esses 
aspectos, compreendidos de forma inseparável, são elementos basilares para a constituição de políticas e práticas democráticas para a primeira infância.

Entretanto, apesar de diferentes estudos e da legislação para a educação infantil reconhecerem a especificidade de creches e pré-escola, as marcas da trajetória dessas instituições ainda prevalecem e, muitas vezes, dificultam a efetivação do direito à educação das crianças de 0 a 5 anos de idade.

De maneira geral, os estudos indicam trajetórias distintas entre as creches (KULHMANN JÚNIOR, 1998; VIEIRA, 1988) e as pré-escolas (GOULART, 2002; KISHIMOTO, 1988; KRAMER, 1987). As primeiras priorizavam a população de baixa renda, tendo como foco a mãe trabalhadora, com preocupações voltadas basicamente à guarda das crianças; o atendimento se dava em período integral e com professoras leigas. As pré-escolas tiveram sua origem marcada pelos jardins da infância, que buscaram, em seu início, adotar uma perspectiva pedagógica diferenciada para as crianças pequenas, mas restrita a uma pequena parcela da população, representante das camadas mais abastadas da sociedade, normalmente em período parcial e com a atuação de professoras. Posteriormente, com a ampliação da oferta de vagas públicas a outras camadas da população, tais instituições foram modificadas e se constituíram nas pré-escolas ou escolas municipais de educação infantil (Emeis), cujo objetivo inicial era a preparação das crianças para o ensino fundamental, com vistas a minimizar o alto índice de reprovação escolar nesse segmento.

Pode-se afirmar que nem a creche, com seu caráter tutelar e substitutivo, nem a pré-escola, com seus objetivos preparatórios e compensatórios vinculados ao ensino fundamental, atendiam à particularidade pertinente à faixa etária de 0 a 6 anos. A creche, pelo atrelamento ao modelo familiar, eximia-se da realização de um trabalho educativo intencional, e a pré-escola, por adotar modelos inspirados no ensino fundamental tradicional, traduzia um processo de escolarização precoce. Em síntese, pode-se dizer que tais instituições encarnaram a polarização entre escolarização precoce e tutela, explicitando a cisão entre o cuidar e o educar e, ainda, a constituição de redes paralelas de educação infantil, com divisão administrativa, pois as creches pertenceriam à Secretaria de Assistência Social e as pré-escolas, à de Educação. Houve também distinção com relação ao caráter de atendimento: enquanto a pré-escola configurou-se no âmbito do atendimento direto, com profissionais e recursos materiais pertencentes ao setor público, as creches expandiram-se por meio do atendimento conveniado com instituições filantrópicas e comunitárias subsidiadas financeiramente com verba pública, tendo o atendimento direto se efetivado em função da pressão dos movimentos sociais.

Atualmente, em grande parte dos municípios brasileiros já ocorreu a integração das creches às secretarias de Educação. Entretanto, apesar de se suprimirem as distinções de ordem administrativa, ainda coexistem, entre essas duas instituições, diferenças na organização do trabalho pedagógico, na composição do quadro de profissionais, na jornada de trabalho das professoras, bem como, permanece o atendimento conveniado nas creches.

As trajetórias distintas de creches e pré-escolas evidenciam uma apropriação inadequada do sentido dos termos "cuidado" e "educação", que contribuíram para a polarização 
entre educação e assistência. A partir da perspectiva do senso comum, assistência é sinônimo de assistencialismo e se refere às atividades de cuidado com o corpo, ações de saúde, higiene e alimentação. Em contrapartida, a educação é compreendida como um conjunto de ações ligadas ao ensino de conteúdos das áreas de conhecimento.

A predominância de pressupostos do senso comum a respeito do cuidado e a educação da criança pequena mostra que, apesar dos avanços legais e das produções acadêmicas sobre a primeira infância, em muitas instituições a criança ainda é tida como objeto de tutela e não como sujeito de direitos. Isso se deve ao fato - mesmo após a inserção das creches no sistema de educação - de que a visão acerca do cuidado ainda se pauta em sua dimensão instrumental, ou seja, ações sobre as crianças na forma de tomar conta, zelar, como se fosse possível educar sem cuidar ou cuidar sem educar.

Faz-se necessário e urgente abordar a dimensão ética do cuidado, considerando sua importância para a existência humana, como é abordado por Boff:

Os dois significados básicos colhidos da filosofia nos confirmam a idéia de que cuidado é mais que um ato singular ou uma virtude ao lado de outras. É um modo de ser, isto é, a forma como a pessoa humana se estrutura e realiza no mundo com os outros. Melhor ainda: é um modo de ser-no-mundo que funda as relações que se estabelecem com todas as coisas (BOFF, 1999, p. 92).

É importante agir com sensibilidade para reconhecer que a criança pequena precisa de afeto e atenção em seu processo de educação. Segundo Guimarães (2011, p. 48):

À medida que tiramos o cuidado de uma dimensão instrumental, de disciplinarização e controle sobre os corpos (na creche, isso significa, por exemplo, dar banho, alimentar, como exigências técnicas e rotineiras somente), para colocá-lo na esfera da existencialidade, ele contribui na concepção de educação como encontro da criança com o adulto, num sentido de diálogo, abertura e experiência compartilhada.

A dimensão ética do cuidado se relaciona à concepção de educação em sua plenitude, que compreende os seres humanos como sujeitos dotados de vontade e capazes de fazer escolhas, intervir na realidade e modificá-la. Uma educação que promove uma convivência entre sujeitos e que é baseada na cooperação e na ajuda mútua faz que a relação não seja de domínio, mas de troca e de interação. Essa visão de educação rompe com o senso comum, que a considera apenas como transmissão de informações e conhecimentos. Ao contrário, trata-se de um conceito amplo e rigoroso, como bem o define Vitor Paro, ao conceber a educação como atualização histórico-cultural:

Supõe-se que os componentes de formação que ela [a educação] propicia ao ser humano são algo muito mais rico e mais complexo do que simples transmissão de informações. Como mediação para a apropriação histórica da herança cultural a que supostamente têm direito os cidadãos, o fim último da educação é favorecer uma vida com maior satisfação individual e melhor convivência 
social. A educação como parte da vida é principalmente aprender a viver com a maior plenitude que a história possibilita. Por ela se toma contato com o belo, com o justo e com o verdadeiro, aprende-se a compreendê-los, a admirá-los, a valorizá-los e a concorrer para sua construção histórica, ou seja, é pela educação que se prepara para o usufruto (e novas produções) dos bens espirituais e materiais (PARO, 2001, p. 37-38).

Nessa perspectiva, a educação na primeira infância em sua integralidade deve ser compreendida como um compromisso ético com a criança, com o intuito de favorecer a autonomia, a autoconfiança, de modo a contribuir positivamente para a formação de sua personalidade, alargando os horizontes cognitivos e emocionais, por meio de relações dialógicas e respeitosas.

Ao reconhecermos a dimensão ética da educação infantil, atentamos também para seu caráter político e para a necessidade de efetivação de novas formas de socialização das crianças na primeira infância, bem como, para a importância de se considerar a infância como um compromisso de toda a sociedade.

As instituições de educação infantil têm potencial para se constituírem como polos de reflexão sobre a educação coletiva das crianças pequenas, como propõe Moss (2009, p. 424), ao conceber a educação infantil como um "fórum público na sociedade civil ou como um canal de encontro e diálogo entre cidadãos, do qual muitas possibilidades podem surgir, algumas já esperadas, outras não, havendo maior produtividade quando as relações são governadas pela prática democrática".

Essa ideia de educação infantil revela o caráter democrático e político do processo de compartilhamento da educação e cuidado da criança entre famílias e educadores, pois, ao conceber a instituição como fórum público, ampliam-se as possibilidades de reflexão sobre a infância e temas desafiadores presentes na educação da criança pequena na atualidade, como "a imagem da criança, a qualidade de vida que queremos para nossos filhos; o que a educação pode e deveria ser; o gênero na creche e em casa" (MOSS, 2009, p. 425). De acordo com o autor, esses e tantos outros temas podem servir como instrumentos de envolvimento na prática democrática nas instituições da primeira infância e são "exemplos do trazer a política para dentro da creche" (MOSS, 2009, p. 425).

Considerando a concepção de educação infantil apresentada, compreende-se que a finalidade da gestão educacional na primeira infância é a garantia dos direitos fundamentais das crianças por meio de um contexto educacional orientado por práticas democráticas, em que o diálogo e a reflexão permanente sobre os desafios do cotidiano são elementos indispensáveis.

\section{OS DESAFIOS DA GESTÃO DEMOCRÁTICA NAS INSTITUIÇÕES DE EDUCAÇÃO INFANTIL}

A gestão democrática não é um tema novo em nosso cenário educacional. Desde 1988, ela figura como um princípio da educação nacional, expresso na Constituição brasileira. Alicerçada pelos princípios da descentralização, da autonomia e da participação, a gestão 
democrática possibilita aos sujeitos envolvidos diretamente na educação definir os rumos do projeto político-pedagógico e das políticas públicas educacionais, de modo a garantir transparência e exercer o controle social sobre o Estado.

No entanto, a constituição da gestão democrática nas escolas e nos sistemas de educação ainda é um ideal a ser perseguido. Os estudos realizados na área de Administração Escolar revelam que as atividades de administração, em geral, reforçam as relações de dominação presentes no interior da sociedade. Isso se dá porque a lógica que rege essa visão é a das empresas capitalistas. Porém, considerando-se a especificidade da gestão escolar, não podemos situá-la com a mesma finalidade da empresa capitalista, criando similaridades entre gestão escolar e empresarial, visto que a natureza da gestão educacional é outra, essencialmente pedagógica.

Teixeira (1968, p. 15) assinala a especificidade da administração escolar:

Em educação, o alvo supremo é o educando, a que tudo mais está subordinado; na empresa, o alvo supremo é o produto material, a que tudo mais está subordinado. Nesta, a humanização do trabalho é a correção do processo de trabalho, na educação o processo é absolutamente humano e a correção de um certo esforço relativo pela aceitação de condições organizatórias e coletivas inevitáveis. São, assim, as duas administrações polarmente opostas.

O conceito amplo de administração como a "utilização racional de recursos para a realização de fins determinados" (PARO, 2000, p. 18) serve como ponto de partida para analisar a administração escolar considerando sua especificidade. Acrescenta-se também, como condição necessária para a constituição da gestão democrática, a compreensão de que a gestão escolar envolve a articulação de todos os trabalhos desenvolvidos na escola, integrando atividades, meios e fins para o seu funcionamento e organização. Segundo Paro (2001, p. 20), "se o administrativo é a boa mediação para a realização do fim e se o fim é o aluno educado, não há mais nada administrativo do que o próprio pedagógico, ou seja, o processo de educá-lo".

Esse conceito de gestão escolar tem como pano de fundo a mudança social e como fim o pedagógico e, portanto, a busca da educação pela e para a democracia. Esta, por sua vez, exige a democratização das relações internas da escola, no que tange seja ao interior da sala de aula seja às relações estabelecidas entre os diferentes sujeitos que compõem a escola: estudantes, professoras, famílias, profissionais de apoio e equipe de gestão.

A gestão democrática nas instituições de educação infantil deve primar pela democratização das relações internas, atentando para três elementos inseparáveis: a relação entre adultos e crianças, entre os adultos que trabalham na instituição e entre os educadores e as famílias. A atenção a tais elementos revela a dimensão política dessas relações no interior da instituição e sua necessária interlocução com os propósitos de uma gestão democrática. Entretanto, é importante acentuar que a democratização das relações internas nas unidades de educação infantil é complexa e requer muito estudo e reflexão, para não atribuir às dimensões das relações interpessoais estabelecidas no cotidiano um caráter reducionista, desvinculado das relações presentes na sociedade. 
A democratização das relações internas nas unidades de educação infantil é uma experiência vital para a aprendizagem de novas formas democráticas de relacionamento no contexto educacional, sem perder de vista que o pano de fundo da gestão democrática é o estabelecimento de uma sociedade democrática sem desigualdades, com oportunidades e qualidade de vida para todos.

Partindo das considerações a respeito do caráter eminentemente democrático da gestão educacional, da concepção de educação integral e da especificidade da educação infantil, é possível afirmar que a gestão democrática nas instituições de educação infantil deve ter como finalidade a garantia dos direitos fundamentais das crianças, expressos no cotidiano por meio da centralidade da criança no projeto pedagógico, da promoção da integração entre cuidado e educação e do seu compartilhamento entre educadores e famílias.

A centralidade da criança no projeto pedagógico ancora-se na compreensão da criança como sujeito de direitos, capaz de participar desde a mais tenra idade de seu processo de formação, e da infância como uma construção social e histórica. Os estudos da Sociologia da Infância (BARBOSA; DELGADO; TOMÁS, 2016; CORSARO, 2011; SARMENTO; PINTO, 2004) contribuem para refletir sobre novas bases para efetivar o trabalho junto à criança pequena, possibilitando uma nova forma de compreendê-la, ao deixar de vê-la apenas por suas fragilidades, valorizando suas potencialidades. As pesquisas destacam a criança pequena como capaz de estabelecer múltiplas interações e participar ativamente em sua formação. Acrescenta-se a isso o avanço nas discussões sobre os direitos das crianças, desencadeado pela Declaração Universal dos Direitos das Crianças em 1989 e, no Brasil, pelo Estatuto da Criança e do Adolescente em 1990, ao conceber as crianças como sujeitos de direitos

Considerar a criança como um ser capaz e como sujeito de direitos possibilita olhá-la em seu momento atual e não como um vir a ser, além de contribuir para romper com o adultocentrismo presente historicamente na organização e estrutura das creches e pré-escolas brasileiras. Os estudos da infância e da criança têm contribuído com os debates atuais sobre a organização das instituições de educação infantil; para Barbosa, Delgado e Tomas (2016, p. 107):

[...] as relações das crianças entre elas e o papel que o encontro, o convívio e os relacionamentos têm do ponto de vista social e individual, são especialmente importantes para que conheçamos seus critérios de pertencimento em alguns grupos, quase nunca marcados pelas faixas de idade, uma vez que esses critérios são demarcações adultocêntricas.

No dia a dia da instituição, a centralidade da criança no projeto pedagógico materializa-se por meio de uma escuta atenta dos bebês e das crianças pequenas, considerando suas demandas de modo a provocar mudanças na rotina e na organização do trabalho pedagógico e promover o protagonismo infantil.

A natureza do compartilhamento da educação da criança pequena entre educadores e famílias nas instituições de educação infantil toma contornos diferentes dos outros seg- 
mentos educacionais. Isso acontece especialmente pela faixa etária das crianças, que exige acompanhamento permanente dos adultos que lhes são próximos. As crianças precisam dos adultos para subsidiá-las, entre outras coisas, na construção de conhecimentos sobre si mesmas e sobre o mundo. Para isso, os adultos precisam compreender suas manifestações e necessidades, o que requer uma observação escrupulosa e a aprendizagem de suas múltiplas linguagens.

Diante da diversidade de organizações familiares e educacionais, faz-se necessário um diálogo permanente para garantir um processo de troca, negociação e descobertas a respeito da educação da criança em contextos educacionais coletivos. O processo de compartilhamento deve fundar-se nos direitos fundamentais das crianças. Para isso, é preciso conhecer e analisar criticamente como se constitui o cotidiano da criança numa instituição educacional e dialogar cotidianamente com as famílias, buscando captar as formas de organização e educação da criança no contexto familiar.

Nesse sentido, uma das principais tarefas da gestão é promover um processo de formação continuada que envolva toda a equipe de profissionais. Essa formação deve ser pautada na leitura e reflexão a respeito do cotidiano à luz dos direitos das crianças e dos conhecimentos produzidos sobre a infância e a criança pequena e sua educação em espaços coletivos. O estudo acerca das práticas cotidianas, longe de pautar-se apenas nas falhas e fragilidades presentes no dia a dia e provocar o desânimo, tem o potencial de construir experiências em que as professoras assumam a autoria da prática pedagógica e, com os demais profissionais da instituição, busquem maneiras de atuação que realmente promovam novas formas democráticas de educação da criança pequena em espaços públicos.

A constituição de uma cultura institucional em que o diálogo e a reflexão permanente sobre as práticas cotidianas se relacionem com a concepção de criança competente e sujeito de direitos é um dos pressupostos para a efetivação de ambiente democrático. É o exercício contínuo e coletivo de se perguntar: o cenário das práticas cotidianas na instituição garante a integração entre cuidado e educação e seu compartilhamento com as famílias, e a participação de todos os sujeitos que compõem a instituição para decisões acerca do trabalho, tendo como eixo norteador o respeito aos direitos das crianças?

O movimento coletivo de buscar alternativas para analisar e constituir novas práticas pode ser potencializado ao se elencarem perguntas que auxiliem a olhar para o contexto institucional, na busca de compreender qual o lugar que a criança realmente ocupa nas instituições. É preciso analisar com rigor se a rotina e as práticas cotidianas são regidas pelas necessidades dos adultos, os conteúdos escolares, as atividades dirigidas, o tempo institucional ou as necessidades e os direitos da criança.

A partir desse questionamento, podem-se averiguar quais são as práticas que favorecem o exercício de princípios democráticos no cotidiano, com o intuito de constatar se os direitos das crianças são efetivados. Pode-se perguntar: qual a visão materializada nas práticas cotidianas acerca dos cuidados com o corpo, alimentação e saúde e as manifestações dos sentimentos das crianças? Todos os momentos da rotina são tematizados e debatidos nas reuniões de formação e fazem parte do planejamento e avaliação do trabalho? As do- 
centes que trabalham diretamente com a criança - professoras, auxiliares - têm uma prática planejada e integrada, sem hierarquização de funções? Quais são as ações que promovem no cotidiano a participação de crianças, profissionais e famílias nas decisões a respeito do trabalho desenvolvido na instituição?

Essas e outras questões podem ajudar a compor um retrato do cotidiano institucional que dê pistas sobre se há iniciativas que promovem a participação e o protagonismo dos atores que compõem a instituição e se as necessidades humanas das crianças - proteção, autonomia, afeto, alimentação e saúde - são realmente consideradas e não reduzidas a ações rotineiras e mecânicas, pautadas em relações de dominação e distanciamento.

Os conteúdos dessas reflexões, para além de contribuir com a efetivação da gestão democrática por meio da qualificação das práticas pedagógicas desenvolvidas e da ampliação de estratégias de participação, podem também favorecer na proposição de ações para a implementação de políticas públicas para a primeira infância.

\section{A gestão na eduCaÇão infantil e os desafios para a escuta das crianças NO COTIDIANO}

A expansão dos estudos e reflexões sobre o cotidiano das instituições tem a potência de produzir reflexões e conhecimentos, de modo a fornecer mais e melhores subsídios à efetivação da gestão democrática nas unidades de educação infantil e no sistema de ensino.

Analisar o cotidiano e torná-lo fonte de estudo é um dos caminhos para que a gestão nas instituições de educação infantil torne-se democrática e considere a escuta à criança como alicerce de todo o trabalho desenvolvido no contexto educativo. É elementar averiguar se no dia a dia as crianças têm o direito de ser, pensar, sentir, querer, viver e sonhar (DALLARI; KORCZAK, 1986), ou seja, se suas necessidades humanas são respeitadas e promovidas em um contexto democrático e solidário.

Os indicadores apresentados no documento Critérios para um atendimento em creches que respeite os direitos fundamentais das crianças (CAMPOS; ROSEMBERG, 2009) podem contribuir para a reflexão a respeito dos princípios que devem guiar a organização do trabalho pedagógico nas unidades de educação infantil. São eles: o direito à brincadeira; o direito à atenção individual; o direito a um ambiente aconchegante, seguro e estimulante; o direito ao contato com a natureza; o direito à higiene e à saúde; o direito a uma alimentação sadia; o direito a desenvolver sua curiosidade, imaginação e capacidade de expressão; o direito ao movimento em espaços amplos; o direito à proteção, ao afeto e à amizade; o direito a expressar seus sentimentos; o direito a uma especial atenção durante seu período de adaptação à creche; o direito a desenvolver sua identidade cultural, racial e religiosa. A articulação dos 12 critérios possibilita o aprofundamento a respeito da singularidade da educação infantil, ao expressar aspectos essenciais para que a criança viva sua infância e tenha satisfeitas, de maneira indissociável, suas necessidades físicas, emocionais e sociais, por meio de uma prática educativa sensível e intencional, que integre educação e cuidado. 
Pesquisas (BARBOSA, 2006; BATISTA, 1998; COUTINHO, 2002; MONÇÃO, 2013; TRISTÃO, 2004) têm constatado que nas instituições de educação infantil comumente prevalece a perspectiva homogênea e rígida de organização da jornada da criança na instituição, que desconsidera suas manifestações e particularidades. Essa perspectiva é materializada na prescrição inflexível de horários, com ações homogêneas, e na forma instrumental e hierarquizada como o cuidado e educação são pensados e vivenciados, sem reflexão, ignorando as necessidades individuais das crianças.

A observação e a escuta das professoras ao longo da pesquisa evidenciaram que, em muitas situações, o espaço da problematização e da reflexão sobre o cotidiano é substituído por reclamações e sensações de desânimo com relação aos desafios da docência na primeira infância. No caso da unidade pesquisada, isso se dava especialmente pelos intensos conflitos entre o grupo de professoras e a equipe de gestão (MONÇÃO, 2013, p. 161-166). Entretanto, em muitas unidades educacionais isso ocorre especialmente com relação às limitações colocadas pela falta de espaço, de materiais pedagógicos e pelo elevado número de crianças, ou seja, pela falta de condições concretas para o desenvolvimento de um trabalho de qualidade com as crianças, fruto de investimentos ainda parcos para essa etapa da educação.

Considerando que o pedagógico está em todas as ações desenvolvidas junto às crianças, a atenção aos diferentes elementos que compõem o cenário das instituições é fundamental. Neste texto, tomaremos como objeto de análise algumas cenas sobre a jornada das crianças na instituição, tendo como foco o modo como se dá a escuta das crianças nos momentos observados.

Tomemos como ponto inicial de análise algumas observações sobre os momentos de entrada e saída das crianças nas unidades de educação infantil, compreendendo-os como ocasiões ricas em possibilidades para efetivar ações de democratização da instituição, por se constituírem como oportunidades para promover o encontro entre equipe de gestão, professoras, famílias e crianças. São espaços privilegiados para a troca de informações e aprofundamento de vínculos, por meio da comunicação diária ancorada no diálogo e na escuta das famílias. Entretanto, apesar de seu potencial para favorecer ações de democratização na instituição, podem-se constituir também como espaços de tensão que, se tratados apenas com soluções emergenciais, sem um aprofundamento dos reais motivos que nutrem os conflitos, podem reforçar as práticas autoritárias e promover o distanciamento entre educadores e familiares.

Muitas crianças chegam à creche alegres, despedem-se dos familiares com tranquilidade e logo se envolvem com outras crianças e nas situações que estão ocorrendo na sala; outras chegam quietas, chorando ou indispostas. Isso tudo depende de como foi a noite da criança e de sua relação com a instituição e seus profissionais. Nesses momentos, as crianças expressam suas necessidades de afeto, de aconchego e de atenção individualizada, seus sentimentos de alegria ou de tristeza.

Em se tratando de crianças pequenas, sabemos que seu bem-estar físico pode ser afetado facilmente: se uma criança não teve uma boa noite de sono, ou teve um mal-estar gástrico, pode necessitar atenção individual, o colo da professora, um tempo maior de sono 
naquele dia ou ficar em um local mais tranquilo na instituição, sem participar das atividades coletivas. Tais situações exigem de todos os profissionais que compõem a instituição flexibilidade para garantir que a rotina daquela criança seja diferenciada e ela tenha atenção especial ao longo do dia. As manifestações e sentimentos das crianças devem ser considerados e respeitados ao longo do período em que permanecem na unidade.

As observações nos momentos de entrada e saída das crianças no CEI pesquisado permitiram perceber como se davam as interações entre as crianças, as famílias e os profissionais. Foi possível constatar a adoção da forma tradicional de funcionamento das escolas e a premissa de que todos precisam fazer tudo ao mesmo tempo, o que dificultava ações que fomentassem uma nova forma de recepcionar as crianças ou se despedir delas, como também uma atenção especial às demandas das crianças.

Pode-se verificar, também, que tanto o horário de entrada como o de saída ocorriam em um curto período, em que os responsáveis levavam as crianças até suas salas e estabeleciam breves diálogos com as professoras, pautados normalmente no relato de alguma intercorrência com a criança, ou simplesmente na entrega da criança e na despedida da família.

Havia situações em que as professoras precisavam conversar mais detalhadamente com as famílias e com a equipe de coordenação e isso normalmente ocorria na sala da direção. O diálogo entre profissionais e famílias é fundamental para a construção de vínculos e confiança dos familiares com relação ao trabalho desenvolvido, além de ser um dos elementos que favorecem a relação de parceria no compartilhamento da educação das crianças. De acordo com Spaggiari (1995, p. 101), a "finalidade maior [é] que o projeto educacional tenha como foco a comunicação-relação entre seus três protagonistas: as crianças, os educadores e as famílias".

Entretanto, apesar da importância destacada, em muitas instituições as famílias ainda são impedidas de acessar as salas onde os bebês e as crianças permanecem, tampouco podem dialogar com as professoras. Apesar de isso ter sido objeto de preocupação de pesquisadores na década de 1980 (HADDAD, 1987; MELLO, 1987), despertando a atenção de educadores e gestores, e das mudanças efetuadas para garantir que as famílias adentrassem as unidades de educação infantil, esse impedimento ainda é recorrente na atualidade. Em pesquisa recente, ao analisar o papel da equipe gestora nas creches conveniadas na rede municipal de São Paulo, Dias (2017) constatou, em uma das instituições, que as famílias eram impossibilitadas de entrar na creche, devendo deixar seus bebês e crianças no portão de entrada, junto a profissionais que não atuariam diretamente com seus filhos. A justificativa da adoção de tal prática por parte da equipe de gestão se pautava na necessidade de organização dos momentos de entrada e saída das crianças, de modo a evitar "transtornos" com o acesso das famílias.

É preciso ficar atento para que as estratégias de organização da rotina se pautem em princípios democráticos e de respeito aos direitos fundamentais das crianças. O impedimento das famílias entrarem nas unidades de educação infantil se afasta contundentemente da perspectiva de uma gestão democrática e reforça práticas autoritárias e até mesmo desumanas. Como as famílias se sentem ao não poder circular no espaço em que seus filhos permanecem 
ao longo do dia? Como as crianças se sentem ao serem impedidas de se despedirem com calma de seus familiares e serem acolhidas por profissionais diferentes todos os dias?

Outro aspecto relevante observado no dia a dia do CEI analisado se refere a um grupo significativo de bebês e crianças pequenas que utilizavam o transporte coletivo escolar e eram acompanhadas pelo condutor do veículo e por uma auxiliar até a sala de referência. A utilização de transporte coletivo escolar pelas crianças pequenas tem aumentado significativamente nos últimos anos, seja pela distância entre a residência da família e a unidade educacional, seja pela coincidência de horários do CEI e do trabalho das famílias, obrigando-as a encontrar alternativas para garantir a frequência da criança. Apesar de constar nas DCNEI, parágrafo $5^{\circ}$. do artigo $5^{\circ}$., que "as vagas em creches e pré-escolas devem ser oferecidas próximas às residências das crianças" (CONSELHO NACIONAL DE EDUCAÇÃO, 2009), nem sempre esse pressuposto é garantido e a oferta de vaga ocorre distante da moradia da criança.

O uso do transporte escolar coletivo na educação infantil provoca alterações no compartilhamento da educação das crianças pequenas, ao inserir mais um adulto - o condutor - nesse processo. No cotidiano do CEI, os condutores muitas vezes assumem o papel dos responsáveis pelas crianças e dialogam com as professoras e equipe de gestão, trazendo informações das famílias sobre as crianças ou levando informações do CEI para os pais. Ao longo do período de observação na unidade, deparou-se com situações em que a diretora da creche chamou a atenção dos condutores com relação à forma de interagir com as crianças e por terem esquecido uma criança ou sua mochila na unidade.

Para além da dinâmica da relação entre educadores e condutores de transporte escolar, é preciso atentar para a interação que a criança estabelece com esse adulto, que não é um familiar nem um educador. Observou-se uma situação em que um condutor ficava em torno de 50 minutos com uma menina do lado de fora da unidade, aguardando a abertura do portão. ${ }^{4}$ Essa situação é preocupante; em se tratando de uma criança pequena, de aproximadamente 2 anos de idade, como será que ela se sentia ao ficar tanto tempo do lado de fora da instituição, com uma pessoa que mal conversava com ela?

Pode parecer uma situação pouco significativa, mas se realmente se busca constituir uma gestão democrática com base na garantia do bem-estar dos bebês e das crianças pequenas é preciso problematizar todas as situações envolvidas, com a intenção de qualificar as práticas cotidianas e apontar elementos que devem ser considerados nas políticas públicas implementadas para a educação infantil.

O momento de saída das crianças também requer atenção e cuidado. Muitas crianças expressam o desejo de permanecer na instituição e relutam em ir embora com seus pais ou responsáveis. O desejo de continuar brincando com seus amigos leva a criança a protestar. É uma situação delicada e sua administração requer cautela, pois muitos familiares ficam

$4 \quad$ O período de funcionamento do CEI pesquisado é das $7 \mathrm{~h}$ às $19 \mathrm{~h}$, sendo o atendimento às crianças realizado das $8 \mathrm{~h}$ às $18 \mathrm{~h}$. No período das $7 \mathrm{~h}$ às $8 \mathrm{~h}$ e das $18 \mathrm{~h}$ às $19 \mathrm{~h}$, diariamente, são feitas reuniões de professoras para a execução dos projetos de estudo e ação (PEA) e hora-atividade individual, destinada ao planejamento de ações junto às crianças. 
incomodados com essa atitude da criança, relacionando-a ao fato de as crianças gostarem mais das professoras do que da família.

A mediação da professora é fundamental para ajudar as famílias a compreender que o contexto educacional é muito atrativo, especialmente por permitir a convivência com outras crianças, evitando situações de conflito pautadas na insegurança das famílias em perder o afeto de seus filhos. Isto foi assinalado na pesquisa de Haddad (1987), em que se verificou que a visão da creche como substituta materna levava as famílias a imaginar que seus filhos nutriam maior afeto pelas docentes, pelo fato da instituição garantir melhores condições materiais, especialmente de alimentação e cuidados de higiene, e a criança permanecer a maior parte do tempo com as profissionais.

Ao encontrar com os familiares ao final do dia, as crianças muitas vezes gostam de lhes mostrar o que têm realizado na instituição, suas produções ou os materiais e espaços onde ficam. É um momento importante em que se pode observar a interação entre pais e filhos e também capturar a visão da criança e das famílias sobre o trabalho desenvolvido com a criança.

Entretanto, nos momentos de saída há também situações de tensão entre docentes e famílias, que são presenciados e sentidos pelas crianças. Isso ocorre quando os familiares se atrasam ou enviam pessoas sem autorização para buscar seus filhos. Em tais momentos, é preciso uma postura acolhedora, para que as crianças não se sintam inseguras e abandonadas pelas famílias, ou expostas aos sentimentos de descontentamento das professoras.

Se se deseja garantir a coerência entre as práticas cotidianas e os direitos conquistados pelas crianças na legislação, considerando a especificidade da criança pequena, é necessária e fundamental a inserção dos momentos de entrada, saída, alimentação, higiene, troca de turno das professoras, momento do descanso, enfim, todos os períodos da rotina diária como temáticas de planejamento e formação. As ações desencadeadas junto às crianças nesses momentos afetam seu desenvolvimento e promovem aprendizagens relativas às relações humanas.

A articulação entre teoria e prática e a reflexão sobre os direitos fundamentais da criança devem ser o norte desse processo reflexivo. Para romper com a cisão entre cuidar e educar e garantir a existência de relações democráticas nas instituições de educação infantil, é essencial reconhecer que nos diferentes momentos ao longo da permanência das crianças na creche o lúdico, o afeto, o acolhimento e a atenção são fundamentais para que as ações com as crianças lhes garantam segurança, bem-estar e o direito de sentir e expressar suas emoções. Segundo Dallari e Korczak (1986, p. 35):

A criança tem o direito de ser tratada como um ser capaz de sentir, que poderá experimentar grande sofrimento se essa característica não for respeitada, e que poderá, ao contrário, desenvolver de modo extraordinário sua condição humana se for favorecida a expansão de seus sentimentos. Na criança os sentimentos ainda estão praticamente desvinculados da razão. Por esse motivo se revelam com mais facilidade e nitidez, reagindo favoravelmente a qualquer estímulo. Mas, ao mesmo tempo, sofrem com maior intensidade os impactos das agressões e repressões e se forem sufocados ou violentados isso acarretará dificuldades para o relacionamento humano da criança e poderá criar problemas muito graves para o desenvolvimento de sua personalidade. 
A atenção aos sentimentos das crianças é um desafio permanente para as professoras e educadores que atuam junto às crianças, tendo em vista que a ideia de que a criança pequena tem de ser controlada ainda é muito presente em nossa sociedade e se expressa no contexto educativo e familiar. Isto requer um olhar sensível e crítico para reconhecer que as crianças, expostas a ações de controle, são concebidas como objetos de tutela, o que, na maioria das vezes, se diferencia frontalmente da concepção de criança como sujeito de direitos apresentada no projeto pedagógico da instituição.

De acordo com Dallari e Korczak (1986, p. 47), "a criança deve ter o direito de querer, de manifestar sua própria vontade, sem medo e constrangimentos". É por meio da expressão dos interesses das crianças que os adultos podem auxiliá-las a compreender o processo de vida coletiva, ajudando-as a perceber o outro e suas necessidades, sem, no entanto, coibir sua liberdade ou suas necessidades.

A gestão democrática na educação infantil pode consolidar-se na medida em que os objetivos das instituições educacionais favoreçam a criança a aprender a escolher, dar sua opinião, expressar suas curiosidades, seus sentimentos e, ao mesmo tempo, considerar as ideias e manifestações dos outros. Garantir a aprendizagem sobre si e sobre o outro, pautada pelos princípios do respeito e da solidariedade, é primordial para a criança desenvolver sua personalidade plenamente, contemplando os aspectos físicos, emocionais e intelectuais.

O papel do adulto é fundamental para a criança pequena, que está numa fase de construção de sua identidade. As formas de cuidar do seu corpo, dar afeto, falar, olhar, adjetivar e nomear suas ações revelam valores, normas e crenças presentes em nossa sociedade e possibilitam que as crianças se apropriem da cultura e desenvolvam sua personalidade. De acordo com Tristão (2004), é um trabalho de sutileza e requer envolvimento do educador e uma observação cuidadosa, para atentar às situações que dependem exclusivamente das professoras e equipe de gestão de cada unidade educativa, na garantia do bem-estar da criança:

\footnotetext{
Essa sutileza está presente em atos cotidianos, aparentemente pouco significativos, mas que revelam a importância do trabalho docente com bebês. Virar uma criança, colocá-la mais perto do grupo, perceber seus sinais corporais, prestar atenção na temperatura ambiente para deixá-la com uma roupa confortável, cobri-la em um dia de frio e outras tantas ações podem fazer a diferença entre a atenção, característica de uma prática humanizadora, plena de significados e o descaso, característico das práticas desumanizadoras, para cada um daqueles meninos e meninas (TRISTÃO, 2004, p. 134-135).
}

As ações sem reflexão podem, mesmo sem a intenção, transformar-se em práticas desumanas com as crianças, contrapondo-se a uma perspectiva acolhedora e humanizadora, em que as interações são o eixo norteador:

Tendo em vista que é na interação com o outro que os afetos e os conhecimentos se constroem, também é aí que se dão as aprendizagens sobre trabalhar com as crianças e como relacionar-se produtiva e democraticamente. A interação qualificada entre os sujeitos de um grupo assegura a construção coletiva de sua proposta político pedagógica (TIRIBA; BARBOSA; SANTOS, 2013, p. 286). 
A disponibilidade para perceber as sutilezas das manifestações das crianças, acolhendo seus sentimentos e emoções, não é um exercício fácil no dia a dia e exige uma postura de abertura e escuta atenta. De acordo com Tonucci (2005, p. 18), "Escutar significa precisar da contribuição do outro. Não basta haver interesse, motivação, convicção de que seja uma boa técnica para envolver as crianças; é preciso sentir, sincera e urgentemente, essa necessidade. É necessário precisar das crianças [...]".

A escuta atenta das manifestações dos bebês e vozes das crianças é um dos pressupostos para constituir relações democráticas com elas. Precisamos compreendê-las como sujeitos e considerar suas expressões como algo necessário para o trabalho pedagógico. Para refletir sobre a complexidade que envolve a escuta das crianças no cotidiano, recorremos a duas cenas observadas e descritas no diário de campo, com uma menina de aproximadamente dois anos e meio de idade, que envolvem os momentos de chegada à instituição em anos diferentes:

Valdirene chegou à sala e não quis brincar com as outras crianças; ao constatar a minha presença, já solicitou meu colo e permaneceu quieta, triste ao longo da manhã.

Após o café da manhã, a professora Karin levou algumas crianças para realizar a troca de fraldas e, ao retornar, Valdirene chorava muito e solicitou novamente meu colo. Acolhi e ela ficou no meu colo chorando por um longo tempo; a professora Karin nem ao menos olhou para ela, demonstrando incômodo com a situação. Depois de um longo tempo, a professora olhou-me e afirmou que não aconteceu nada no banheiro. Segundo ela, Valdirene começou a chorar quando me viu, e exclamou incomodada: "Valdirene está querendo um atendimento VIP hoje". Tempos depois, quando as crianças foram para a sala multiuso, Valdirene permaneceu com a mesma atitude de não querer brincar. Pergunto à professora Jerusa a respeito da possibilidade de a Valdirene não estar se sentindo bem e, neste momento, chega à sala a supervisora. Ela vê a criança no meu colo e pergunta o que está acontecendo com a criança e a professora Jerusa diz à supervisora que Valdirene "estava sentimental hoje" e busca um termômetro para medir sua temperatura e constata que a criança está com 37,5 graus de temperatura.

Mais tarde, as crianças já estão no refeitório para almoçar, vejo de longe Valdirene choramingando, mas almoçando. De repente, observo que a professora Karin transfere Valdirene da mesa em que estava. Perguntei à professora o que aconteceu, e ela me informa que Valdirene vomitou.

Aproximo-me novamente de Valdirene. Ela chora muito e, como percebo que a professora não fez a higiene após o vômito, pego papel toalha e faço uma higiene superficial para tirar o excesso do vômito de sua roupa. A professora serve a sobremesa: maçã e água. Pergunto se Valdirene vai comer, pois acabou de vomitar, ela dá uma resposta evasiva. Valdirene come a maçã e segue para o banheiro com a turma toda. Observo que Valdirene não é priorizada para a higiene, mesmo estando com as roupas sujas de vômito. Percebo que Valdirene perturba muito a professora, pois continua chorando muito.

Ao retornarem para a sala, as professoras trocam as roupas das crianças, e novamente Valdirene não é priorizada. Depois de um tempo, a professora troca Valdirene e a deita no colchonete, a criança adormece. Não ocorre nenhuma atitude de acolhida em relação à criança (MONÇÃO, 2013, p. 225-226). 
Um ano depois, Valdirene já está em outra sala, com outra professora, e registro uma nova situação no início do ano letivo:

Várias crianças chegam com a equipe do transporte coletivo (motorista e auxiliar). As crianças são levadas às respectivas salas. Valdirene anda devagar, chora muito e se distancia do condutor do transporte, que não percebe que ela chora. Após entregar as outras crianças, o motorista constata que Valdirene está chorando sozinha no corredor, pega-a no colo e a leva até sua sala.

Minutos depois, vou até a sala e converso com a professora, que está sentada na sua mesa. As crianças estão realizando atividades diversificadas, algumas conversam com ela na mesa, outros brincam e Valdirene está sozinha encostada na parede, triste. Pergunto sobre a Valdirene e a professora diz que ela voltou faz poucos dias, pois fez uma cirurgia na garganta, e afirma "que criança é assim mesmo" e que não pode também ficar muito "em cima".

No momento do café, observo Valdirene sentada, triste. Ela se levanta, vai até a professora Tuany e diz que quer a mãe. A professora de Valdirene conversa com outra professora a respeito da criança e fazem algum comentário, mas não a acolhem. Valdirene retorna para seu lugar e chora até que a professora Tuany a repreende, pedindo que pare de chorar (MONÇÃO, 2013, p. 226).

O que essas cenas nos revelam? Por que, mesmo em momentos distintos, Valdirene chegou à instituição requerendo uma atenção especial e não foi acolhida pelas professoras?

Essas e outras situações são terrenos férteis para refletirmos sobre ações - intencionais ou não - que promovem a invisibilidade de Valdirene e de tantas outras crianças no cotidiano, especialmente pela ausência de escuta e acolhimento em situações em que elas se sentem inseguras.

No caso de Valdirene, parece que ainda predomina a máxima do senso comum, que diz que a criança está com "manha" e que, se a acolhermos, ela vai desejar ficar o tempo todo no colo ou com atenção exclusiva do adulto. Isso não é verdade, pois as crianças, salvo nas situações em que não estão bem, expressam que seu desejo maior é o de explorar novas situações e interagir com outras crianças e objetos.

Nesse sentido, as interpretações superficiais das manifestações da criança a partir de generalizações, sem se atentar ao que ela está expressando ou sentindo, revelam que a escuta ainda não ocorreu e, portanto, o diálogo não se fará presente.

As situações vividas por Valdirene revelam a necessidade de se aguçar o olhar sobre as relações entre adultos e crianças no interior das instituições de educação infantil em momentos - nesse caso, os períodos de chegada ao CEI - que não são considerados importantes para compor os espaços de formação continuada e planejamento. É preciso considerar que, historicamente, a postura de desconfiança dos adultos em relação às crianças é recorrente: os adultos julgam as ações delas no lugar de buscar compreendê-las e assumem uma postura autoritária, muitas vezes sem se darem conta disso.

Korczak (1997, p. 204) alerta com relação às práticas de desatenção às crianças, questionando: "olhá-la com frieza e má vontade para lhe mostrar desaprovação, não será um castigo?" O autor afirma, ainda, que de nada adianta mudar a forma de punição, pois qual- 
quer ação de coação ou violência tem como pano de fundo a noção de que a disciplina só pode ser imposta, destacando que se pode "fustigar a sensibilidade, o amor próprio da criança, da mesma maneira como antigamente se fustigavam seus corpos" (KORCZAK, 1997, p. 204).

As relações entre adultos e crianças, materializadas nas práticas cotidianas, são permeadas de incongruências, próprias das relações humanas. Isso se dá especialmente pelo fato de a criança pequena ainda estar muito ligada ao plano das emoções. Por esse motivo, essas contradições precisam ser compreendidas como o resultado de um trabalho coletivo - de todos que atuam nas instituições - e não individual, e colocadas como elementos que carecem de reflexão e análise para alicerçar a prática docente.

No âmbito das unidades de educação infantil, é necessário considerar o fato de que tanto as ações de cuidado com o corpo físico como as experiências para ampliar o repertório das crianças com relação ao conhecimento do mundo, promovidas pelas professoras junto às crianças, são permeáveis também às emoções dos adultos e precisam ser refletidas sem julgamento, mas considerando a dimensão humana da prática pedagógica e a necessidade da escuta atenta das professoras.

Trata-se de uma missão complexa se se considera que, nas bases educacionais tradicionais, a relação entre adultos e crianças era pautada pelo autoritarismo, por meio de práticas de coerção, agressão física e castigos. A superação dessas práticas é um desafio que envolve toda a sociedade e deve ser objeto de preocupação e atenção permanente, até que a escuta e consideração das manifestações das crianças seja algo inerente ao trabalho pedagógico e elemento constituinte das políticas públicas.

$\mathrm{Na}$ medida em que os gestores das políticas públicas assumirem o compromisso de promover recursos e propostas que favoreçam a efetivação de práticas pedagógicas em que as crianças sejam realmente protagonistas, veremos a transformação das instituições educacionais da primeira infância em espaços de aprendizagem para todos, em um fórum público.

A implementação de políticas públicas para a primeira etapa da educação básica com poucos recursos financeiros, desconsiderando as especificidades dessa faixa etária, com a falta de conhecimentos e reflexão sobre como fazer uma prática diferente, provoca no cotidiano das instituições posturas de distanciamento e rigidez. Assim, para avançar na democratização das relações com as crianças é preciso considerar a importância de se constituírem políticas e práticas pautadas nos direitos fundamentais das crianças e na escuta permanente de suas vozes e manifestações, como também garantir a escuta e relações dialógicas com as professoras, profissionais e famílias que compõem a instituição.

\section{CONSIDERAÇões FINAIS}

Ao longo deste texto, buscaram-se evidenciar algumas cenas do cotidiano de uma instituição de educação infantil que podem servir como elementos de reflexão sobre a garantia ou não dos direitos das crianças e, por conseguinte, a constituição da gestão democrática nas instituições de educação infantil. 
Ao compreendermos que a finalidade da educação é o pleno desenvolvimento da personalidade humana e a garantia ao respeito pelos direitos do ser humano e pelas liberdades fundamentais, como consta no artigo 26 da Declaração Universal dos Direitos Humanos, é necessário que se fique atento e se contraponha a ações - intencionais ou não - que promovem a invisibilidade e o cerceamento das ações das crianças, desconsiderando sua singularidade.

Destaca-se o papel da equipe de gestão no enfrentamento dessa discussão no âmbito interno das instituições, entendendo que a democratização das instituições de educação infantil pressupõe um olhar aguçado para todas as ações desenvolvidas junto às crianças no cotidiano. Para isso, o trabalho dos profissionais que atuam com a primeira infância precisa ser reconhecido em sua especificidade, com garantia de condições objetivas para sua efetivação. A equipe de gestão precisa empreender esforços para constituir um trabalho coletivo que prime por relações democráticas, ultrapassando a mera troca de informações e conhecimentos: é salutar construir e cultivar diariamente uma convivência respeitosa, acreditando que o trabalho democrático com as crianças pequenas, apesar de sua complexidade, é possível.

Para que as professoras atuem junto às crianças por meio de relações democráticas, elas precisam vivenciar uma experiência de trabalho pautada em um projeto político-pedagógico que considere a criança, as famílias e as professoras como sujeitos dotados de vontade e capazes de modificar o cotidiano.

A escuta da criança como norte das práticas cotidianas não pode ser alcançada por decreto ou imposição: deve resultar da ampla reflexão e de estudos sobre formas dialógicas de relação entre adultos e crianças. A constituição de um trabalho coletivo que garanta a inserção da pesquisa e da indagação como pressuposto das práticas cotidianas precisa considerar o contexto social e político em que está inserido, bem como, a maneira como a sociedade acolhe e reconhece a infância.

Nessa perspectiva, trata-se de ampliar e aprofundar a discussão junto aos profissionais e famílias sobre o cotidiano das crianças em profundidade, legitimando a especificidade da educação infantil, sem medo de lidar com as temáticas da democracia, dos conflitos, do afeto, do cuidado, dos sentimentos, das emoções, e reconhecer que as instituições de educação infantil têm o cuidado e a educação como a dimensão política da existência humana.

Considerar os direitos das crianças como preocupação central para desenvolver o trabalho nas instituições de educação infantil é tarefa urgente e a finalidade da gestão nas instituições de educação infantil. Repensar a maneira como as crianças são vistas, assim como compreender que os processos democráticos são dialéticos e comportam tensões que retratam os embates das forças sociais presentes na sociedade, é fundamental para sustentar as iniciativas de práticas democráticas e não desanimar com as dificuldades. Esse debate envolve toda a comunidade escolar, porque professoras devem ouvir as crianças e serem ouvidas, assim como pais e gestores, portanto, o diálogo é contínuo e a reflexão coletiva pode ajudar a vencer as dificuldades inerentes ao trabalho, especialmente em momentos em que o contexto social não está favorável a ampliação de experiências democráticas. 
Trata-se do desejo de escutar criticamente para construir, com crianças, educadores e famílias, instituições de educação infantil democráticas, em que as estratégias de convivência coletiva, de respeito ao outro, de organização e do espírito de justiça guiem o trabalho desenvolvido.

\section{REFERÊNCIAS}

ANDRÉ, M. E. D. A. Estudo de caso em pesquisa e avaliação educacional. Brasília, DF: Liberlivros, 2008.

BARBOSA, M. C. S. Por amor e por força: rotinas na educação infantil. Porto Alegre: Artmed, 2006.

BARBOSA, M. C. S.; DELGADO, A. C. C.; TOMÁS, C. A. Estudos da infância, estudos da criança: Quais campos? Quais teorias? Quais questões? Quais métodos? Inter-Ação, Goiânia, v. 41, n. 1, p. 103-122, jan./abr. 2016.

BATISTA, R. A rotina no dia a dia da creche: entre o proposto e o vivido. Dissertação (Mestrado em Educação) - Centro de Ciências da Educação, Universidade Federal de Santa Catarina, Florianópolis, 1998.

BOFF, L. Saber cuidar: ética do humano, compaixão pela terra. Petrópolis: Vozes, 1999.

BRASIL. Constituição (1988). Constituição da República Federativa do Brasil: promulgada em 5 de outubro de 1988. Brasília, DF, 1988.

CAMPOS, M. M.; ROSEMBERG, F. Critérios para um atendimento em creches que respeite os direitos fundamentais das crianças, 6. ed. Brasília, DF: MEC/SEB, 2009.

CONSELHO NACIONAL DE EDUCAÇÃO. Câmara de Educação Básica. Resolução nº.5, de 17 de dezembro de 2009. Fixa as Diretrizes Curriculares Nacionais para a Educação Infantil. Brasília, DF, 2009. Disponível em: http://portal.mec.gov.br/index. php?option=com content\&view=article\&id=13684\%3Aresolucoes-ceb. Acesso em: 6 mai. 2013.

CORSARO, W. A. Sociologia da infância. Tradução Lia Gabriele Regius Reis. Porto Alegre: Artmed, 2011.

COUTINHO, A. M. S. As crianças no interior da creche: a educação e o cuidado nos momentos de sono, higiene e alimentação. Dissertação (Mestrado em Educação) - Centro de Ciências de Educação, Universidade Federal de Santa Catarina, Florianópolis, 2002. 
DALLARI, D. de A.; KORCZAK, J. O direito da criança ao respeito. São Paulo: Summus, 1986.

DECLARAÇÃO UNIVERSAL DOS DIREITOS HUMANOS. Adotada e proclamada pela Assembleia Geral das Nações Unidas (resolução 217 A III) em 10 de dezembro 1948. Paris, 1948. Disponível em: https://www.unicef.org/brazil/declaracao-universal-dos-direitos-humanos. Acesso em: 7 nov. 2019.

DIAS, S. R. R. C. O papel da equipe gestora nas creches conveniadas na rede municipal de São Paulo, 2017. Dissertação (Mestrado em Educação) - Programa de Pós-Graduação em Educação, Universidade Cidade de São Paulo, 2017.

GOULART, A. L. Educação pré-escolar e cultura. São Paulo: Cortez, 2002.

GUIMARÃES, D. Relações entre adultos e bebês na creche: o cuidado como ética. São Paulo: Cortez, 2011.

HADDAD, L. A relação creche-família: relato de uma experiência. Cadernos de Pesquisa, São Paulo, v. 60, p. 70-78, fev. 1987.

KISHIMOTO, T. M. A pré-escola em São Paulo (1877 a 1940). São Paulo: Loyola, 1988.

KORCZAK, J. Como amar uma criança, 4. ed. Rio de Janeiro: Paz e Terra, 1997.

KRAMER, S. A política do pré-escolar no Brasil: a arte do disfarce. Rio de Janeiro: Dois Pontos, 1987.

KUHLMANN JÚNIOR, M. Infância e educação infantil: uma abordagem histórica. Porto Alegre: Mediação, 1998.

MELlO, A. M. Tempo de mudança na creche Vila Praia. Cadernos de Pesquisa, São Paulo, n. 60, p. 79-84, fev. 1987.

MONÇÃO, M. A. G. Gestão democrática na educação infantil: o compartilhamento da educação da criança pequena, 2013. Tese (Doutorado em Educação) - Faculdade de Educação, Universidade de São Paulo, São Paulo, 2013.

MOSS, P. Introduzindo a política na creche: a educação infantil como prática democrática. Psicologia USP, São Paulo, v. 20, n. 3, p. 417-436, jul./set. 2009.

PARO, V. H. Administração escolar: introdução crítica, 9. ed. São Paulo: Cortez, 2000.

188 Comunicações | Piracicaba | v. 26 | n. $23 \mid$ p. 167-189 | set.-dez. 2019 
PARO, V. H. Escritos sobre educação. São Paulo: Xamã, 2001.

SARMENTO, M. J.; PINTO, M. As culturas da infância nas encruzilhadas da segunda modernidade. In: SARMENTO, M. J.; CERISARA, A. B. Crianças e miúdos: perspectivas sociopedagógicas da infância e educação. Porto: ASA, 2004, p. 9-34.

SPAGGIARI, S. A parceria comunidade-professor na administração das escolas. In: EDWARDS, C.; GANDINI, L. FORMAN, G. As cem linguagens da criança. Porto Alegre: Artmed, 1995, p. 105-112.

TEIXEIRA, A. S. Natureza e função da administração escolar. In: TEIXEIRA, A. S. et al. Administração escolar. Salvador: Anpae, 1968, p. 9-17.

TIRIBA, L.; BARBOSA, S. N.; SANTOS, N. O cotidiano da educação infantil: buscando interações de qualidade. In: KRAMER, S.; NUNES, M. F.; CARVALHO, M. C. (Org.). Educação infantil: formação e responsabilidade. Campinas, SP: Papirus, 2013.

TONUCCI, F. Quando as crianças dizem: agora chega! Porto Alegre: Artmed, 2005.

TRISTÃO, F. C. D. Ser professora de bebês: um estudo de caso em uma creche conveniada. Dissertação (Mestrado em Educação) - Centro de Ciências da Educação, Universidade Federal de Santa Catarina, Florianópolis, 2004.

VIEIRA, L. M. F. Mal necessário: creches no Departamento Nacional da Criança (19401970). Cadernos de Pesquisa, São Paulo, n. 67, p. 3-16, 1988.

\section{Dados da AUtora:}

Maria Aparecida Guedes Monção

Doutora em Educação pela Faculdade de Educação da Universidade de São Paulo. São Paulo/SP-Brasil. Professora do Curso de Pedagogia e do Programa de Pós-Graduação em Educação da Faculdade de Educação da Universidade Estadual de Campinas. Campinas/ SP-Brasil.maguedes@unicamp.br

Submetido em: 23-3-2019

Aceito em: 11-11-2019 